\title{
ENTRE A FILOSOFIA E AS CIÊNCIAS SOCIAIS
}

\author{
Between Philosophy and Social Sciences
}

\begin{abstract}
Alessandro Cavassin Alves ${ }^{1}$
RESUMO: O presente artigo busca pensar os limites entre Filosofia e Ciências Sociais, e que, apesar de serem conhecimentos distintos, estão muito mais imbricadas do que separadas, devido ao seu caráter reflexivo e lógico sobre os temas que intrigam a humanidade. Um problema conjunto é o próprio caráter do que fundamentaria a sociedade. Tal motivação provém de um exemplo particular, que é pensar a existência de um ente superior e anterior aos indivíduos, capaz de dar sentido à existência, mas também de moldá-los, pelo seu poder coercitivo. O exercício é pensar como Plotino, no século III, chamou a existência dessa força superior de Inteligência (Nô̂s). E Durkheim, no final do século XIX, que marcou o início da sociologia científica, chamou-a de Sociedade. Este exercício quer demonstrar como as Ciências Sociais, tendo como referência Durkheim, utiliza da Filosofia para explicar o significado da vida em sociedade.
\end{abstract}

PALAVRAS-CHAVE: Plotino; Inteligência (Noûs); Filosofia; Durkheim; Ciências Sociais.

ABSTRACT: The present article tries to think the limits between Philosophy and Social Sciences, and that, although they are distinct knowledge, are much more intertwined than separated, due to its reflective and logical character on the themes that intriguing the humanity. A joint problem is the very character of what would underpin society. A joint problem is the very character of what would underpin society. This motivation comes from a particular example, which is to think of the existence of a superior and prior entity, capable of giving meaning to existence, but also of molding them, by its coercive power. The exercise is to think as Plotinus, in the third century, called the existence of this superior force of Intelligence (Noûs). And Durkheim, in the late nineteenth century, which marked the beginning of scientific sociology, called it Society. This exercise wants to demonstrate how the Social Sciences, having as reference Durkheim, uses of the Philosophy to explain the meaning of the life in society.

KEYWORDS: Plotinus; Intelligence (Noûs); Philosophy; Durkheim; Social Sciences.

As Ciências Sociais buscam compreender seu objeto de pesquisa, a sociedade e o indivíduo em suas relações sociais, com métodos científicos de coletas de dados e de verificação, que por sua vez, compreende uma teoria explicativa discursiva dos mesmos

\footnotetext{
${ }^{1}$ Doutor em Sociologia pela Universidade Federal do Paraná (UFPR). Professor na Faculdade São Basílio Magno (FASBAM) e na Secretaria de Estado da Educação do Paraná (SEED-PR). E-mail: alessandrocavassin@gmail.com
} 
métodos, como bem apontam Bourdieu, Chamboredon e Passeron ${ }^{2}$. A teoria sociológica envolve, portanto, a necessidade de um pensamento racional e lógico para justificar e sistematizar o conhecimento empírico que produz, aproximando-a da característica básica do conhecimento filosófico.

Neste sentido, as teorias sociológicas podem ser consideradas tais como teorias filosóficas, apenas que com sua especificidade voltada para a sociedade e com suas metodologias empíricas. Afinal, filosofias sociais, desde Aristóteles, nada mais fizeram do que pensar a sociedade racionalmente. E ainda, como disse Raymond Aron, "poderse-ia alegar, porém (é o que farei pessoalmente), que todos os grandes sistemas sociológicos implicam uma concepção sobre o homem e a história. Dizer que uma doutrina sociológica contém elementos filosóficos não é depreciá-la"3.

Entretanto, o século XIX marcou o início das Ciências Sociais propriamente ditas. E a proposta realizada por Auguste Comte (1798-1857) e o positivismo, tinha como objetivo explícito delimitar o campo de uma ciência para a sociedade, nos mesmos moldes e metodologia das ciências da natureza. Mas, de certa forma, isto não se concretizou, devido ao caráter específico da sociedade e dos indivíduos em suas relações sociais, que permitiam as mais variadas interpretações ${ }^{4}$.

Dessa forma, o positivismo de Auguste Comte, o materialismo histórico dialético de Karl Marx (1818-1883) e Friedrich Engels (1820-1895), o funcionalismo de Émile Durkheim (1858-1917), a sociologia compreensiva de Max Weber (1864-1920), enquanto "fio genealógico" das Ciências Sociais, são exemplos claros da necessidade da Filosofia para dar sentido às suas teorias empíricas, ao apresentar diversas formas de se compreender um mesmo objeto, que é a sociedade e as relações sociais. E esse "fio" está "longe de ser contínuo e uniforme", afirma Michel Lallement ${ }^{5}$. Isso é visível nas excelentes e diversas produções científicas do universo social que avançaram significativamente no século XX, com suas mais diversas perspectivas de análise e pontos de vista, e mesmo da institucionalização desta ciência.

\footnotetext{
${ }^{2}$ Cf. BOURDIEU, Pierre; CHAMBOREDON, Jean-Claude; PASSERON, Jean Claude. A profissão de sociólogo. Petrópolis, RJ: Vozes, 1999, p. 10.

${ }^{3}$ ARON, Raymond. As etapas do pensamento sociológico. 6. ed. São Paulo: Martins Fontes, 2003, p. 561.

${ }^{4} \mathrm{Cf}$. GIDDENS, Anthony. Novas regras do método sociológico. Uma crítica positiva das sociologias compreensivas. Rio de Janeiro: Zahar Editores, 1978, p. 11-22. Afirma Giddens: "Contudo, uma certa esperança de um Newton nas ciências sociais continua sendo bastante comum, ainda que hoje talvez os que são céticos a respeito de tal possibilidade sejam mais numerosos do que os que ainda alimentam tal esperança. Mas aqueles que ainda esperam por um Newton, além de estarem esperando por um trem que não vai chegar, estão também na estação errada". GIDDENS. Op. cit., p.13.

${ }^{5}$ Cf. LALLEMENT, Michel. História das ideias sociológicas: de Parsons aos contemporâneos. Petrópolis, RJ: Vozes, 2004, p.7.
} 
O presente artigo, então, realiza um exercício de comparação entre duas teorias, a primeira, de caráter filosófico, de Plotino, do século III d.C., e a segunda, uma teoria científica social, de Émile Durkheim, formulada no final do século XIX. O filósofo neoplatônico Plotino não reflete sobre a sociedade, mas sobre o que dá sentido às coisas e que se encontra exterior ao mundo sensível, sua filosofia sobre o Uno, a Inteligência (Nô̂s) e a Alma ${ }^{6}$. Émile Durkheim, um dos fundadores da Sociologia científica, não reflete sobre o Uno, a Inteligência ou a Alma, mas também busca entender o que dá sentido à existência, delimitando suas reflexões aos indivíduos que interagem entre si e se associam. Para tanto, denomina de Sociedade esse ente exterior e fatos sociais os objetos de estudo da Sociologia ${ }^{7}$. Assim, a Sociedade e a Inteligência teriam uma precedência ontológica sobre os indivíduos e sobre os seres em geral ${ }^{8}$.

Portanto, a Inteligência para Plotino seria um conceito similar a Sociedade para Durkheim? Quando Durkheim afirma que a Sociedade é uma realidade existente por si mesma, não seria esse um argumento de caráter filosófico? E, como autores tão díspares e distantes cronologicamente podem ser aproximados? Acredita-se que, buscar essas respostas contribui epistemologicamente para se pensar a necessária conexão entre Filosofia e Ciências Sociais e, igualmente, a importância do conhecimento filosófico e sociológico na construção da compreensão da existência humana.

\section{A Inteligência (Noûs) para Plotino}

Plotino (Licópolis, Egito, 205 - Roma, 270 d.C.) pertenceu ao círculo de Amônio, em Alexandria, "permanecendo até 243 d.C., ano em que deixou Alexandria para seguir o imperador Gordiano em sua expedição oriental. Fracassada a expedição, devido à morte do imperador, Plotino decidiu ir para Roma”, e a partir do ano 254, abriu uma escola nesta capital, na qual passou a ensinar e posteriormente a escrever seus ensinamentos, até que seu discípulo Porfírio ordenou seus tratados, nominando-os com o título de Enéadas. Suas aulas eram bastante frequentadas, inclusive por políticos e até mesmo pelo imperador

\footnotetext{
${ }^{6}$ Cf. PLOTINO. A Alma, a Beleza e a Contemplação. Tradução de Ismael Quiles. São Paulo: Associação Palas Athena, 1981. Seus tratados estão publicados em forma completa com o título Enéadas.

${ }^{7}$ Cf. DURKHEIM, Émile. As regras do método sociológico. 15. ed. São Paulo: Editora Nacional, 1995.

${ }^{8}$ Há muitos outros temas e debates sobre a Filosofia e a Sociologia destes dois autores. Entretanto, o presente texto limita-se a discutir brevemente o significado dos conceitos Inteligência para Plotino e Sociedade para Durkheim, com o objetivo de, ao aproximá-los, comparativamente, demonstrar o complexo limite entre Filosofia e Ciências Sociais e, ao mesmo tempo, de como ambos podem ser pensados de forma conjunta.
} 
Galiano e sua mulher Solonina, a tal ponto que chegaram a examinar um projeto seu de fundar uma cidade de filósofos, a Platonópolis, cujos habitantes teriam de "observar as leis de Platão, ou seja, viver realizando a união com o divino. O projeto fracassou devido às tramas dos cortesãos"

A filosofia de Plotino identifica a Inteligência como o segundo "nível" na escala hierárquica da processão ${ }^{10}$. O primeiro seria o Uno-Bem, princípio primeiro absoluto, princípio supremo de unidade. A terceira seria a Alma, da qual as demais almas procedem. Portanto, "para Plotino a realidade se articula em três hipóstases (= substâncias): o Uno, a Inteligência/Espírito, e a Alma""11.

O filósofo Cícero Cunha Bezerra assim comenta sobre a Inteligência em Plotino:

Plotino, no tratado oitavo da terceira Enéada, define a Inteligência não como uma coisa particular, mas como algo universal e múltiplo. Universal porque abarca todos os seres e múltiplo porque coexistem, em sua natureza, simultaneamente, o inteligente (Inteligência) e o inteligível (ser):

"[...] a Inteligência é os seres e os contêm todos dentro de si, não como em um lugar, mas como quem se contém a si mesmo e é uma só coisa com eles" (En. VI, 9, 6).

Poderíamos dizer que a Inteligência em Plotino corresponde às Ideias de Platão, à Forma aristotélica e ao deus supremo dos estoicos, mas com uma particularidade: Plotino é o primeiro filósofo grego que não coloca a Inteligência como princípio supremo. A Inteligência é um deus, mas, um deus múltiplo que contém todos os seres e, por isso, é modelo do mundo sensível. Ao mesmo tempo em que a Inteligência é representada como uma "ordem inteligível", é pensamento de si mesma. (... $)^{12}$.

Fica claro que, sobre as coisas sensíveis, acima dos indivíduos e suas almas, há uma 'substância', de 'ordem inteligível' (diferente da característica do Uno, como não inteligível), que dá sentido às coisas desse mundo, pois 'abarca todos os seres' e esses 'coexistem' em sua natureza. Assim, a Inteligência 'contém todos os seres' sendo o 'modelo do mundo sensível' e 'pensamento de si mesma'. Portanto, em outros termos, pode-se dizer que ela é exterior aos indivíduos, mas que se volta aos mesmos, conferindolhes ou conformando-lhes suas características próprias. E ela é universal e múltipla ao mesmo tempo.

A Inteligência é, do ponto de vista da ética, o que arrasta o homem em direção à perfeição. Com o termo "arrastar" queremos dizer "ser levado" por um desejo autêntico de querer alcançar a Beleza que está acima das coisas sensíveis. O espírito deve elevar-se acima das ideias e contemplar a bondade total e una. Plotino fala de um apaixonar-se. O filósofo autêntico é um apaixonado que sente as dores do parto ao contemplar algo belo, mas que não se contenta com a beleza dos corpos e foge para as belezas da alma, regressando, desse modo, para a pátria bem ordenada por justas leis. $(. . .)^{13}$.

\footnotetext{
${ }^{9}$ Cf. REALI, Giovanni; ANTISERI, Dario. História da filosofia: filosofia pagã antiga. v.1. São Paulo: Paulus, 2003, p. 358.

${ }^{10}$ Cf. BEZERRA, Cícero Cunha. Compreender Plotino e Proclo. Petrópolis, RJ: Vozes, 2006, p. 80.

${ }^{11}$ REALI; ANTISERI. Op.cit., p. 355.

12 BEZERRA, Op.cit., p. 78-79 [grifos no original].

${ }^{13}$ BEZERRA. Op.cit., p. 80 [grifos no original].
} 
Da mesma forma, as almas, provenientes da Alma, que é proveniente da Inteligência, leva a razão a reconhecer sua existência, e a buscar a verdadeira ordem da qual tudo emana, encaminhando, da mesma forma, toda a ação e contemplação, até o apaixonar-se por ela. A ética tem, assim, uma finalidade de ação que encontra sentido fora deste mundo, para uma pátria 'bem ordenada por justas leis', e que todo ser busca reconhece-la ou entende-la. Assim, de forma natural e necessária, há a atração para essa 'exterioridade', para a Inteligência.

Para Plotino, tudo na Inteligência está em ato e, por isso, nela ser e pensar são o mesmo, dado que é impossível separar Inteligência e inteligível. As coisas são, platonicamente, imagens de uma "Forma real" 14 .

Plotino reforça uma característica importante da Inteligência, a de 'ser e pensar', da impossibilidade de 'separar Inteligência e inteligível', reforçando sua autonomia e sua substancialidade e, ao mesmo tempo, sua multiplicidade.

No tratado nove da quinta Enéada, Plotino afirma a teoria platônica da participação das coisas nas ideias perfeitas que subsistem em si mesmas como um todo. Vale dizer que participação, em Plotino, não significa "imitação". As ideias, ao contrário do que comumente se entende, não estão isoladas. Cada Forma particular é uma Inteligência particular ao modo dos teoremas que, em seu conjunto, formam uma ciência. A conclusão que obtemos é que a noção de Inteligência culmina na compreensão da vida como puro pensamento. É uma atividade que tem como finalidade o conhecer-se a si mesmo. Pensar a si mesmo é pensar todas as coisas. Nesta frase vemos a dialética platônica se converter numa realidade metafísica $^{15}$.

Por fim, a Inteligência garante a existência das coisas sensíveis, onde "tudo está em ato", e que concede aos mesmos suas especificidades, via participação na mesma e não significando mera "imitação". Daí a frase "pensar a si mesmo é pensar todas as coisas".

Para Plotino, a Alma, a terceira hipóstase, da mesma forma, seria una e múltipla, distribuindo a "vida por todas as partes":

Não vamos duvidar que uma só alma, e uma mesma coisa, possa estar em muitos lugares. Não admitilo é negar que haja um ser que sustenta e que dirige todas as coisas, que as sustenta abraçando-as todas e que as dirige com sabedoria, um ser que é múltiplo, porque as coisas são múltiplas, mas que é uno porque o ser que o contém todo deve ser uno. Por sua unidade multiplicada distribui a vida por todas as partes; por sua unidade indivisível dirige-as com sabedoria. Nas coisas que não têm sabedoria há um princípio diretivo que imita esta unidade da alma sábia ${ }^{16}$.

A partir desta breve apresentação desta teoria racional filosófica, tendo como foco a Inteligência para Plotino, se questiona, novamente, se ela não poderia ser identificada na formulação da teoria científica do sociólogo Émile Durkheim, porém com o nome de

${ }^{14}$ BEZERRA. Op.cit.p. 81 [grifos no original].

${ }^{15}$ Idem [grifos no original].

${ }^{16}$ PLOTINO. Op. cit., p.38. A essência da Alma, II. Enéada IV, 2, 2. 
Sociedade? Enfim, teria a Sociedade para Durkheim o significado similar ao de Inteligência para Plotino?

A seguir, busca-se apreender o significado de Sociedade para Durkheim.

\section{A Sociedade para Durkheim}

Émile Durkheim é considerado um dos fundadores da Sociologia científica. Entretanto, sua trajetória intelectual, em seu início, é marcada pelo curso de Filosofia. "Durkheim é, por formação, um filósofo de universidade francesa" "17, diz Raymond Aron. Da mesma forma, Aron questiona se Durkheim não teria feito, em nome da sociologia, uma filosofia social, e de que foi, portanto, mais filósofo do que sociólogo? ${ }^{18}$ Apesar dessa realidade de formação, Durkheim, ao longo de sua trajetória, buscou ser o portador da defesa dessa nova ciência. Mas, até que ponto é possível dissociar Ciências Sociais e Filosofia?

A trajetória intelectual de Durkheim inicia com a sua nomeação, em 1887, como professor de Pedagogia e de Ciências Sociais na Faculdade de Letras da Universidade de Bordeaux, na França. "Trata-se do primeiro curso de sociologia criado em uma universidade francesa" ${ }^{19}$. Assim, sua produção intelectual a partir da década de 1890 estava voltada para transformar a Sociologia, posteridade de Auguste Comte, em uma real ciência da sociedade, tendo como referência o grande desenvolvimento das ciências naturais.

Em sua tese de doutoramento, em 1893, com o título Da divisão do trabalho social ${ }^{20}$, buscou entender as transformações sociais do mundo contemporâneo. Para ele, viver em coletividade significava a necessidade do consenso, em que os indivíduos, associados, encontrariam nela sentido para viver, dado por padrões que a própria sociedade imporia, como qualquer outro organismo vivo (uma célula, por si só, pouco ou nada significa frente ao corpo). Assim, a sociedade estaria acima dos indivíduos e de suas consciências individuais, formando uma consciência coletiva que, por sua vez, orienta e conduz a ação de seus membros, pelo seu caráter coercitivo. O indivíduo que não segue os padrões sociais acaba, de uma maneira ou outra, sendo punido por sanções coletivas.

\footnotetext{
${ }^{17}$ ARON. Op. cit., p. 453.

${ }^{18}$ Cf. ARON. Op. cit., p. 561.

${ }^{19}$ ARON. Op. cit., p. 578.

${ }^{20}$ Cf. DURKHEIM, Émile. Da divisão do trabalho social. 2. ed. São Paulo: Martins Fontes, 1999.
} 
A moderna divisão do trabalho, entretanto, teria enfraquecido a consciência coletiva (por exemplo, comparando-as com sociedades tradicionais, na qual a mesma seria forte o suficiente para que seus membros saibam, o tempo todo, o que fazer); daí a necessidade, frente a um estado de anomia, que novas configurações de solidariedade e de moral pudessem ficar claras aos indivíduos modernos, gerando novamente o consenso. Porém, esta "nova" solidariedade ou "nova" moral deve ser um movimento proveniente da própria sociedade, acontecendo de forma coletiva, reafirmando seu poder sobre o indivíduo.

Assim, Raymond Aron enfatiza que a ideia central de toda a Sociologia durkheimiana é a "que pretende que o indivíduo nasce da sociedade, e não que a sociedade nasce do indivíduo" ${ }^{21}$, até como contraposição aos filósofos contratualistas e mesmo retomando a ideia aristotélica. Assim, o salto filosófico de Durkheim estaria em considerar a sociedade em seus dois sentidos, ela como real, sendo um conjunto de indivíduos em associação, mas, principalmente, ela como ideal, origem natural da organização humana que, consequentemente, molda o seu comportamento. Sem o todo, sem a Sociedade ideal, externa e anterior a todos, não haveria humanidade. Tal concepção filosófica vai ser defendida ao longo de toda a sua trajetória intelectual. Afinal, todo indivíduo nasce dentro de uma sociedade e, por isso, não é possível que ele a forme ${ }^{22}$.

Em 1895, Durkheim publica, então, As regras do método sociológico, na qual defende o objeto e o método de estudo da Sociologia, que por sua vez, a diferenciaria das outras ciências e, consequentemente, da Filosofia. Eis a definição de fato social:

É fato social toda maneira de agir fixa ou não, suscetivel de exercer sobre o indivíduo uma coerção exterior; ou então ainda, que é geral na extensão de uma sociedade dada, apresentando uma existência própria, independente das manifestações individuais que possa ter ${ }^{23}$.

Durkheim defendeu que os 'fatos sociais' são exteriores aos indivíduos, independentes da consciência individual e de caráter geral. Os fatos sociais deveriam ser tratados como "coisas", não que "sejam coisas materiais, e sim que constituem coisas tais como as coisas materiais, embora de maneira diferente" ${ }^{24}$. A linguagem, os padrões de comportamento, a religião, a moral, a moda, a família, o crime, a educação, o direito, enfim, seriam fatos

\footnotetext{
${ }^{21}$ ARON. Op. cit., p. 464.

${ }^{22}$ Tânia Quintaneiro, assim define a sociedade em Durkheim: "Vemos que, ao explicitar sua concepção de sociedade, o sociólogo francês mostra-nos uma realidade que tem vida própria, é como um ente superior, mais perfeito e que, afinal, antecede e sucede os indivíduos; independe deles e possui sobre eles uma autoridade que, embora constrangendo-os, eles amam". QUINTANEIRO, Tânia. Um toque de clássicos: Marx, Durkheim e Weber. 2. ed. rev. amp. Belo Horizonte: Editora UFMG, 2002, p.76.

${ }^{23}$ DURKHEIM. Op. Cit., 1995, p. 11 [grifos no original].

${ }^{24}$ DURKHEIM. Op. cit., 1995, p. XXI.
} 
sociais, enquanto "coisas" visíveis, objetos concretos de estudo da Sociologia. Eis a sociedade real. Porém, insiste Durkheim, os fatos sociais apenas se tornaram possíveis de existir devido a uma Sociedade ideal pré-existente; esses fatos são originados da Sociedade ideal que, por sua vez, não impõe um único modelo de comportamento, mas permite a multiplicidade de culturas de acordo com o desenvolvimento de cada povo.

\footnotetext{
Em virtude deste princípio, a sociedade não é simples soma de indivíduos, e sim sistema formado pela sua associação, que representa uma realidade específica com seus caracteres próprios. Sem dúvida, nada se pode produzir de coletivo se consciências particulares não existirem; mas esta condição necessária não é suficiente. É preciso ainda que as consciências estejam associadas, combinadas, e combinadas de determinada maneira; é desta combinação que resulta a vida social, e, por conseguinte, é esta combinação que a explica. Agregando-se, penetrando-se, fundindo-se, as almas individuais dão nascimento a um ser, psíquico se quisermos, mas que constitui individualidade psíquica de novo gênero. É, pois, na natureza desta individualidade, e não nas das unidades componentes, que é preciso ir buscar as causas próximas e determinadas dos fatos que nela se produzem ${ }^{25}$.
}

Durkheim, ao ressaltar essa "individualidade psíquica de novo gênero", que também pode ser chamada de consciência coletiva, diz que "não é necessário hipostasiar" tal individualidade, mas, para o autor, não há dúvidas de que "os estados que a constituem diferem especialmente daqueles que constituem as consciências particulares" ${ }^{26}$. O nascer das consciências individuais, apenas reafirma a independência da Sociedade, como préexistente, sem a qual as consciências individuais associadas não teriam sentido.

Enfim, e é também o que se quer pensar, até que ponto essa sua definição de Sociedade e seus fatos sociais não se aproximam da hipóstase Inteligência de Plotino?

Durkheim, já no prefácio da segunda edição do livro As regras do método sociológico, reconheceu a crítica dirigida a ele, de estar a pensar a Sociologia via Filosofia. Entretanto, buscou reafirmar sua convicção daquilo que, para ele, era específico da Ciência Social, para que seu objeto não se confundisse com outros ${ }^{27}$.

Apesar desta defesa, pela especificidade do objeto da Sociologia (os fatos sociais, a sociedade, a consciência coletiva), sua solução não deixou de ser filosófica? Sim, foi uma solução filosófica. Mas, confirmar, via Filosofia, a afirmação de uma realidade que se impõe ao indivíduo em nada desmerece sua teoria. Acredita-se que não seria possível defende-la se Durkheim não insistisse na defesa dessa realidade que se impõe aos indivíduos quando os mesmos estão associados.

\footnotetext{
${ }^{25}$ DURKHEIM. Op. cit., 1995, p. 90-91.

${ }^{26}$ DURKHEIM. Op. cit., 1995, p.90 (nota 1).

${ }^{27}$ Cf. DURKHEIM. Op. cit., 1995, p. XXIX.
} 
Em 1897 Durkheim publica o livro $O$ suicídio, obra empírica que analisa esse fato social, enquanto exemplo significativo na compreensão do significado da Sociedade (real e ideal) e sua influência sobre o indivíduo.

Em 1902, como consagração de sua carreira, transfere-se para a importante universidade de Sorbonne e em 1906 foi nomeado titular da cadeira de Pedagogia da Faculdade de Letras de Paris, onde ensinou paralelamente Pedagogia e Sociologia, e que em 1913 recebeu o nome de "Cátedra de Sociologia da Sorbonne"28, delimitando esse campo de estudo. Em 1912 publica seu livro da maturidade, As formas elementares da vida religiosa, que identifica na "religião primitiva" a melhor forma de se estudar a Sociedade ideal ${ }^{29}$.

Este problema de limites entre Filosofia e Ciência Social acompanhou Durkheim ao longo de toda sua trajetória. Como exemplo, a seguir apresentam-se duas longas citações do autor. A primeira do livro "Sociologia e Filosofia", publicado postumamente, em 1925, na qual ele defenda sua tese da existência da Sociedade.

Desde o momento, pois, em que o homem concebe ideais, mais ainda, desde o momento em que não pode passar sem concebê-los e sem aferrar-se a eles, o homem é um ser social. É a sociedade que o impele e o obriga a elevar-se de tal modo sobre si mesmo e a que o provê, ademais, dos meios para lográ-lo. É apenas a sociedade que faz com que o homem adquira consciência de si, que o eleva e o leva a um nível de vida superior. Mas a sociedade não pode chegar a constituir-se sem a crença em um ideal. Estes ideais não são outra coisa que as ideias nas quais se reflete e resume a vida social, tal como existe nos momentos culminantes de seu desenvolvimento.

Diminui-se a sociedade quando não se vê nela mais que um corpo organizado que tem por objetivo cumprir certas funções vitais. O certo é que neste corpo vive uma alma: é o conjunto dos ideais coletivos. Mas estes ideais não são ideais abstratos, frias representações intelectuais desprovidas de toda eficácia, mas são essencialmente motores, uma vez que atrás deles há forças reais e atuantes: são estas as forças coletivas, forças naturais em consequência, ainda que morais, comparáveis às forças que atuam no resto do universo.

O ideal mesmo é uma força deste gênero. Sua ciência pode, pois, ser construída.

$\mathrm{O}$ ideal provém da realidade, mesmo que a ultrapasse; por isso pode se incorporar a ela.

Os elementos que constituem o ideal são, pois, tomados da realidade, mas se encontram combinados de uma nova maneira. É precisamente a novidade desta combinação que produz a novidade do resultado. Abandonado a si mesmo, jamais o indivíduo teria conseguido, sozinho, extrair os materiais necessários para uma tal construção. Deixado só às suas forças, como teria conseguido o homem ter tanto a ideia como o poder de superar-se a si mesmo $?^{30}$

${ }^{28}$ Cf. ARON. Op.cit., p. 577-579.

${ }^{29}$ Cf. DURKHEIM, Émile. As formas elementares de vida religiosa: o sistema totêmico na Austrália. São Paulo: Paulinas, 1989. Tânia Quintaneiro apresenta, em Durkheim, como as cerimônias religiosas são significativas para se entender o que é a Sociedade: "as cerimônias religiosas cumprem um importante papel ao colocarem a coletividade em movimento para sua celebração: elas aproximam os indivíduos, relembram a eles que são membros de um mesmo grupo, multiplicam os contatos entre eles, tornam-nos mais íntimos e 'por isso mesmo, o conteúdo das consciências muda. Em dias comuns, as preocupações utilitárias e individuais são as que ocupam mais os espíritos'. Assim, a energia intrínseca aos sentimentos sociais consegue manter os membros unidos entre si" QUINTANEIRO. Op. cit., p.97. O mesmo significado pode ser dado ao Estado, a um clube de futebol, a uma associação de bairros, a um agrupamento profissional, a um sindicato etc.

${ }^{30}$ DURKHEIM, Émile. Sociologia e Filosofia. São Paulo: Ícone, 1994, p.139. 
Buscando compreender Durkheim, o "tomar consciência de si" significa reconhecerse um ser social e que estaria subordinado ou englobado em algo maior do que ele mesmo, a própria Sociedade, que por sua vez, reflete um ideal que deve ser seguido por todos. A educação seria a instituição, na sociedade moderna, que melhor proporcionaria aos indivíduos esta tomada de consciência e o natural reconhecimento dos ideais sociais.

Durkheim, inclusive, menciona no parágrafo acima a questão da "alma", que está no corpo, como sinônimo do "conjunto de ideias coletivas". A alma individual reflete o coletivo da qual ela pertence. Esse coletivo, esse ideal, está posto na realidade concreta, mas a ultrapassa, pois se encontra combinada de uma nova maneira. Naturalmente, a alma humana reconheceria a necessidade de superar-se a si mesma moldando-se ao ideal social.

Nesse sentido, para o sociólogo, seria impossível acreditar que a consciência humana seria mero epifenômeno da vida física, como já se discutia em sua época. Ao contrário, ela tem vida própria para além da realidade material ${ }^{31}$.

A segunda citação de Durkheim é retirada do livro "Lições de Sociologia", também publicado postumamente, em 1950, em que discute o significado da Sociedade.

\begin{abstract}
Assim, a história parece mesmo provar que o Estado não foi criado e não tem simplesmente o papel de impedir que o indivíduo não seja perturbado no exercício de seus direitos naturais, mas é o Estado que cria esses direitos, organiza-os e torna-os realidades. E, com efeito, o homem só é homem porque vive em sociedade. Retire-se do homem tudo o que é de origem social e não restará mais do que um animal análogo aos outros animais. Foi a sociedade que o elevou tão acima da natureza física, e ela alcançou esse resultado porque a associação, agrupando as forças psíquicas individuais, intensifica-as, leva-as a um grau de energia e de produtividade infinitamente superior ao que poderiam atingir se continuassem isoladas umas das outras. Surge assim uma vida psíquica de novo tipo, infinitamente mais rica, mais variada do que aquela de que o indivíduo solitário poderia ser o palco, e a vida que assim se produz, penetrando o indivíduo que dela participa, transforma-o. No entanto, por outro lado, ao mesmo tempo que a sociedade assim alimenta e enriquece a natureza individual, ela tende inevitavelmente a submetêla, e isso pela mesma razão. Exatamente porque o grupo é uma força moral tão superior às das partes, $\mathrm{o}$ primeiro tende necessariamente a subjugar as segundas. Estas não podem deixar de se colocar sob sua dependência. Trata-se aí de uma lei mecânica moral, tão inelutável quanto as leis da mecânica física. Todo grupo que dispõe de seus membros sob coação se esforça para modelá-los à sua imagem, para impor-lhes suas maneiras de pensar e de agir, para impedir as dissidências. Toda sociedade é despótica, a menos que algo exterior a ela venha conter seu despotismo. Não quero dizer, por outro lado, que esse despotismo tenha algo de artificial; ele é natural uma vez que é necessário e que, além do mais, em certas condições, as sociedades não podem se manter de outro modo. Tampouco quero dizer que ele seja insuportável; pelo contrário, o indivíduo não o sente, assim como não sentimos a atmosfera que pesa sobre nossos ombros. A partir do momento em que o indivíduo foi elevado dessa maneira pela coletividade, ele naturalmente quer o que ela quer, e aceita sem dificuldade o estado de sujeição a que se encontra reduzido. Para que ele tenha consciência disso e lhe resista, é preciso que aspirações individualistas tenham surgido, e elas não podem surgir nessas condições. (...). Somos muito mais livres em meio a uma multidão do que num pequeno grupo ${ }^{32}$.
\end{abstract}

Alguns temas vão sendo retomados paralelamente, como a questão do Estado político.

Para o autor, o Estado seria um reflexo do ideal social, quando cria, organiza e torna

${ }^{31}$ DURKHEIM. Op. cit., 1994, p. 13.

${ }^{32}$ DURKHEIM, Émile. Lições de Sociologia. São Paulo: Martins Fontes, 2002, p.84-85. 
realidade, por exemplo, determinados direitos essenciais à vida social. Enfim, o Estado não teria uma origem contratual, mas ele existe naturalmente para criar e defender interesses coletivos. Poderia, portanto, ser qualquer outra forma política de organização, enquanto manifestação da Sociedade.

Nesse mesmo parágrafo, Durkheim insiste na defesa da Sociedade como uma "vida psíquica de novo tipo", capaz de transformar a todos, submetendo o todo, enquanto força moral. O exemplo latente dessa força moral é o grupo. $\mathrm{O}$ indivíduo isolado ou com a exasperação de suas aspirações individualistas e egoístas ao extremo seria prejudicial a um consenso e levaria a um estado de anomia se isso se generalizasse ${ }^{33}$.

Durkheim vem a falecer em 15 de novembro de 1917, com 59 anos.

\section{Conclusão}

Como visto, a Sociedade para Durkheim é muito mais do que a junção de pessoas vivendo em uma determinada comunidade. A Sociedade é um ente, uma substância, que está acima de todos, e é o todo, na qual dá sentido às ações humanas, mas, ao mesmo tempo, por ser inteligível precisa que racionalmente se debruce sobre sua manifestação, via fatos sociais, via uma metodologia científica. A Sociedade, enquanto ente é perceptível pelos fatos sociais e seu caráter coercitivo. Da mesma forma, a Inteligência para Plotino abarca todos os seres e na qual coexistem o inteligente e o inteligível e a Filosofia seria o guia para a compreensão da mesma.

Eticamente, as duas realidades, Inteligência e Sociedade, arrastam os indivíduos em sua direção, pois elas são a perfeição da qual todo ser almeja conhecer. Ambas, também, fazem com que o espírito humano eleve-se acima das coisas sensíveis. Em Plotino a Inteligência é um deus múltiplo, da mesma forma que, também, Durkheim afirma que a Sociedade é um deus, se assim se desejar. Esse “deus" não seria o Uno em Plotino, nem o princípio criador de todas as coisas cristão, mas aquilo que daria sentido às coisas.

Como dito, o filósofo Cícero Cunha Bezerra citava Plotino dizendo: "a Inteligência é os seres e os contêm todos dentro de si, não como em um lugar, mas como quem se contém a si mesmo e é uma só coisa com eles" (En. VI, 9, 6). Da mesma forma, parafraseando

\footnotetext{
${ }^{33}$ Para Tania Quintaneiro, Durkheim deixa claro que a sociedade é a autoridade moral, é ela que confere às normas morais seu caráter obrigatório. "Em toda a sua obra, Durkheim procura comprovar os princípios que fundamentam sua concepção de sociedade. Esta, se nada mais fosse do que uma soma dos indivíduos que a constituem, não poderia ter valor moral superior à soma do valor moral de cada um de seus elementos" QUINTANEIRO. Op. cit., p.94.
} 
Plotino, pode-se dizer que: "a Sociedade é os individuos e os contêm todos dentro de si, não como em um lugar, mas como quem se contém a si mesmo e é uma só coisa com eles”. E ainda, para Bezerra, "poderíamos dizer que a Inteligência em Plotino corresponde às Ideias de Platão, à Forma aristotélica e ao deus supremo dos estoicos”, e pode-se acrescentar, "à Sociedade para Durkheim”.

Enfim, para além do exercício de comparação entre o filósofo Plotino e o sociólogo Durkheim, o presente texto quis reforçar a ideia de proximidade entre Filosofia e Ciências Sociais. Durkheim é um exemplo de cientista que se depara com o tênue limite entre a Ciência Social que deseja construir e a Filosofia, base de toda reflexão racional, pois, ao fazer ciência, em especial, a ciência social, o autor, consciente ou inconscientemente, acabava utilizando da metafísica para justificar sua tese científica sobre o significado de sociedade. E Plotino, da mesma forma, continua sendo uma referência filosófica fundamental, exemplo de construção teórica racional e lógica capaz de explicar a realidade humana.

\section{Referências}

ARON, Raymond. As etapas do pensamento sociológico. 6. ed. São Paulo: Martins Fontes, 2003.

BEZERRA, Cícero Cunha. Compreender Plotino e Proclo. Petrópolis, RJ: Vozes, 2006.

BOURDIEU, Pierre; CHAMBOREDON, Jean-Claude; PASSERON, Jean Claude. $A$ profissão de sociólogo. Petrópolis, RJ: Vozes, 1999.

DURKHEIM, Émile. As formas elementares de vida religiosa: o sistema totêmico na Austrália. São Paulo: Paulinas, 1989.

. Sociologia e Filosofia. São Paulo: Ícone, 1994.

1995. . As regras do método sociológico. 15. ed. São Paulo: Editora Nacional, . Da divisão do trabalho social. 2. ed. São Paulo: Martins Fontes, 1999. . Lições de Sociologia. São Paulo: Martins Fontes, 2002.

GIDDENS, Anthony. Novas regras do método sociológico. Uma crítica positiva das sociologias compreensivas. Rio de Janeiro: Zahar Editores, 1978.

LALLEMENT, Michel. História das ideias sociológicas: de Parsons aos contemporâneos. Petrópolis, RJ: Vozes, 2004. 
PLOTINO. A Alma, a Beleza e a Contemplação. Tradução de Ismael Quiles. São Paulo: Associação Palas Athena, 1981.

QUINTANEIRO, Tânia. Um toque de clássicos: Marx, Durkheim e Weber. 2. ed. rev. amp. Belo Horizonte: Editora UFMG, 2002, p.76.

REALI, Giovanni; ANTISERI, Dario. História da filosofia: filosofia pagã antiga. v.1. São Paulo: Paulus, 2003. 